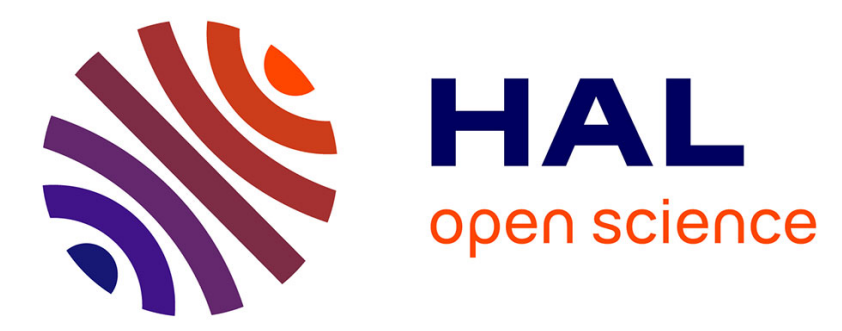

\title{
Amphipathic DNA Polymers Inhibit Hepatitis C Virus Infection by Blocking Viral Entry
}

Takuya Matsumura, Zongyi Hu, Takanobu Kato, Marlene Dreux, Yong-Yuan Zhang, Michio Imamura, Nobuhiko Hiraga, Jean-marc Juteau, Francois-loic Cosset, Kazuaki Chayama, et al.

\section{To cite this version:}

Takuya Matsumura, Zongyi Hu, Takanobu Kato, Marlene Dreux, Yong-Yuan Zhang, et al.. Amphipathic DNA Polymers Inhibit Hepatitis C Virus Infection by Blocking Viral Entry. Gastroenterology, 2009, 137 (2), pp.673-681. 10.1053/j.gastro.2009.04.048 . hal-03295634

\section{HAL Id: hal-03295634 https://hal.science/hal-03295634}

Submitted on 22 Jul 2021

HAL is a multi-disciplinary open access archive for the deposit and dissemination of scientific research documents, whether they are published or not. The documents may come from teaching and research institutions in France or abroad, or from public or private research centers.
L'archive ouverte pluridisciplinaire $\mathbf{H A L}$, est destinée au dépôt et à la diffusion de documents scientifiques de niveau recherche, publiés ou non, émanant des établissements d'enseignement et de recherche français ou étrangers, des laboratoires publics ou privés. 


\title{
Amphipathic DNA Polymers Inhibit Hepatitis C Virus Infection by Blocking Viral Entry
}

\author{
TAKUYA MATSUMURA ${ }^{*}$, ZONGYI HU ${ }^{*}$, TAKANOBU KATO ${ }^{*}$, MARLENE DREUX $\ddagger$, YONG- \\ YUAN ZHANG ${ }^{*}$, MICHIO IMAMURA $\$$, NOBUHIKO HIRAGA $\$$, JEAN-MARC JUTEAU\|, \\ FRANCOIS-LOIC COSSET ${ }^{\ddagger}$, KAZUAKI CHAYAMA§, ANDREW VAILLANT ${ }^{\|}$, and T. JAKE \\ LIANG*
}

"Liver Diseases Branch, National Institute of Diabetes and Digestive and Kidney Diseases, National Institutes of Health, Bethesda, Maryland FUniversite de Lyon, INSERM U758, and Ecole Normale Superieure de Lyon, Lyon, France §Department of Medicine and Molecular Science, Division of Frontier Medical Science, Graduate School of Biomedical Sciences, Hiroshima University, Hiroshima, Japan "REPLICor Inc, Laval, Quebec, Canada

\begin{abstract}
BACKGROUND \& AIMS-Hepatitis C virus (HCV) gains entry into susceptible cells by interacting with cell surface receptor(s). Viral entry is an attractive target for antiviral development because of the highly conserved mechanism.

METHODS-HCV culture systems were used to study the effects of phosphorothioate oligonucleotides (PS-ONs), as amphipathic DNA polymers (APs), on HCV infection. The in vivo effects of APs were tested in urokinase plasminogen activator (uPA)/severe combined immunodeficient (SCID) mice engrafted with human hepatocytes.

RESULTS-We show the sequence-independent inhibitory effects of APs on HCV infection. APs were shown to potently inhibit $\mathrm{HCV}$ infection at submicromolar concentrations. APs exhibited a size-dependent antiviral activity and were equally active against HCV pseudoparticles of various genotypes. Control phosphodiester oligonucleotide (PO-ON) polymer without the amphipathic structure was inactive. APs had no effect on viral replication in the HCV replicon system or binding of $\mathrm{HCV}$ to cells but inhibited viral internalization, indicating that the target of inhibition is at the postbinding, cell entry step. In uPA/SCID mice engrafted with human hepatocytes, APs efficiently blocked de novo HCV infection.
\end{abstract}

CONCLUSIONS-Our results demonstrate that APs are a novel class of antiviral compounds that hold promise as a drug to inhibit HCV entry.

Hepatitis C virus (HCV) infects approximately 200 million people worldwide. ${ }^{1}$ The majority of HCV-infected patients fails to clear the virus, and many develop chronic liver disease including cirrhosis with a risk of hepatocellular carcinoma. Treatment of chronic hepatitis $\mathrm{C}$

\footnotetext{
(C) 2009 by the AGA Institute

Reprint requests Address requests for reprints to: T. Jake Liang, MD, LDB/NIDDK/NIH, Bldg 10-9B16, 10 Center Dr, Bethesda, Maryland. JakeL@bdg10.niddk.nih.gov; fax: (301) 402-0491..

Supplementary Data

Note: To access the supplementary material accompanying this article, visit the online version of Gastroenterology at www.gastrojournal.org, and at doi: 10.1053/j.gastro.2009.04.048.

Conflicts of interest

The authors diclose the following: J.-M.J. and A.V. are employees of REPLICor, Inc. The remaining authors disclose no conflicts.
} 
is currently based on peginterferon-alfa and ribavirin, which is accompanied by substantial adverse effects and is only effective in approximately half of the patients.2, 3 In addition to other viral targets, viral entry is an attractive target for antiviral development because of the potentially conserved mechanism of viral entry. 4 Although several candidate receptors for HCV have been identified, $5^{-10}$ the mechanism of HCV entry still remains largely unknown. Previous reports have indicated a $\mathrm{pH}$ dependency for entry of $\mathrm{HCV}$ pseudoparticles (HCVpp) as well as cell culture-generated $\mathrm{HCV}(\mathrm{HCV} c \mathrm{c})$, suggesting that $\mathrm{HCV}$ enters cells by receptormediated endocytosis.7,11,12 Antiviral compounds targeting the entry step of viral infection have been successfully developed in other viral infections.13 Recent studies have shown that phosphorothioate oligonucleotides (PS-ONs), as amphipathic DNA polymers (APs), have a sequence-independent anti-viral activity against human immunodeficiency virus type 1 (HIV-1) as entry inhibitors. ${ }^{14}$ The antiviral effect of APs appears to be specific to the phosphorothioate backbone, which confers an amphipathic structure, because the phosphodiester oligonucleotides (PO-ONs) as nonamphipathic polymers are ineffective.14

\section{Materials and Methods}

\section{Cell Culture and Oligonucleotide Synthesis}

Huh7.5 (provided by Charles Rice), Huh7.5.1 (provided by Francis Chisari), Huh7, and Hep3B cells were maintained at $37^{\circ} \mathrm{C}, 5 \% \mathrm{CO}_{2}$ in Dulbecco's modified Eagle medium, containing $10 \%$ fetal bovine serum. All PS-ONs and PO-ONs were synthesized as described previously. 14 Oligonucleotides lacking the phosphorothioate modification (PO-ONs) were synthesized with the addition of 2'-O-methyl ribose modification, which stabilizes oligonucleotides from nuclease degradation. ${ }^{14}$ Compounds used in the in vivo experiment were synthesized under good manufacturing practice (GMP) conditions to yield high-purity sodium salts.

\section{HCV Infection and Replication Assays}

The production of cell culture-generated HCV JFH-1 (HCV cc) and HCV pseudovirus (HCVpp) has been reported previously ${ }^{5}, 15$ and is described in detail in the Supporting Document. HCVpp harboring E1/E2 glyco-proteins from genotypes 1a, 1b, 2a, 3a, 4a, 5a, and 6 a were described previously. ${ }^{16}$ For viral internalization assay, Hep3B cells were incubated for 1 hour at $4{ }^{\circ} \mathrm{C}$ to allow binding of $\mathrm{HCVpp}$ (pHCV7a) to cells, washed repeatedly with phosphate-buffered saline to remove unbound virus, and treated with concanamycin A (SigmaAldrich, St. Louis, MO) $(25 \mathrm{nmol} / \mathrm{L})$, Anti-E2 AP33 antibody ${ }^{17}(25 \mu \mathrm{g} / \mathrm{mL})$, PS-ON (100 nmol/ $\mathrm{L})$, or PO-ON $(100 \mathrm{nmol} / \mathrm{L})$ overnight at $37^{\circ} \mathrm{C}$ for viral entry. The efficiency of infection was measured by luciferase assay 24 hours later. Transient assay of genotypes $1 \mathrm{~b}$ (Con-1) and $2 \mathrm{a}$ (JFH-1) subgenomic reporter replicons have been reported previously ${ }^{18,}, 19$ and are described in detail in the Supporting Document.

\section{HCV Binding and Fusion Assays}

The HCV-like particle (LP) binding assay was performed at $4^{\circ} \mathrm{C}$ for 1 hour in $100 \mu \mathrm{L}$ of TNC $(50 \mathrm{mmol} / \mathrm{L}$ Tris, $\mathrm{pH} 7.4,100 \mathrm{mmol} / \mathrm{L} \mathrm{NaCl}, 1 \mathrm{mmol} / \mathrm{L} \mathrm{CaCl} 2$ ) buffer containing $1 \%$ bovine serum albumin as reported previously ${ }^{20}$ and is described in detail in the Supporting Document. Both Hep3B and Huh7.5 cells were tested. Direct binding of PS-ON or PO-ON to HCV-LP was measured by a plate-binding assay and is described in the Supporting Document. For viral fusion assay, $\mathrm{HCV}$ pp/lipo-some lipid mixing assays with rhodamine-labelled liposomes were performed as previously reported ${ }^{21}$ and are described in the Supporting Document.

\section{HCV Infection in Chimeric Mice}

Human hepatocyte-transplanted mice generated in severe combined immunodeficient (SCID)/ urokinase plasminogen activator (uPA) mice were purchased from PhenixBio (Hiroshima, 
Japan). ${ }^{22}$ These uPA/SCID mice stably transplanted with human hepatocytes were treated intraperitoneally with $10 \mathrm{mg} / \mathrm{kg}$ of poly C PS-ON or poly AC PS-ON (40mer) on days $-1,0$, $1,3,5$, and 7 . Control poly $\mathrm{C}$ PO-ON (40mer stabilized by 2'-O-methyl ribose modification) was also tested. A fourth group of mice did not receive any compounds (only normal saline administration). Approximately 5-15 mice were included in each group. The mice were intravenously inoculated on day 0 with $\mathrm{HCV}$ patient serum containing $3.9 \times 10^{3}$ copies of $\mathrm{HCV}$ genotype $1 \mathrm{~b}$. Serum samples were obtained on days 0 (prior to HCV inoculation), 7, 14, 21, 28 , and 35 for HCV RNA, HCV core antigen, and human albumin determination. Human albumin in the blood of the chimeric mice was measured with the Alb-II Kit (Eiken Chemical, Tokyo, Japan).

\section{Statistical Analysis}

Data from at least triplicate experiments were averaged and expressed as means \pm standard deviations. Statistical analysis was performed using the Student $t$ test or Welch $t$ test. $P$ values of less than .05 were considered statistically significant.

\section{Results}

\section{APs Inhibit HCV Infection in a Sequence-Independent Manner}

To assess whether APs can inhibit HCV infection, fully degenerate 40mer oligonucleotides that were either phosphorothioated (PS-ON) resulting in a stable amphipathic DNA polymer or that had a 2'-O-methyl modification on the ribose moiety (PO-ON) conferring stability but not altering the polyanionic nature of $\mathrm{DNA}^{14,23}$ were tested. Huh7.5 cells were infected with $\mathrm{HCV} c \mathrm{in}$ the presence of either PS-ON or PO-ON. At 72 hours postinfection, HCV-infected cells were assessed by immunofluorescence assay (Figure $1 A$ ) and intracellular HCV RNA quantification (Figure $1 B$ ). HCV infection was significantly inhibited by PS-ON and not PO$\mathrm{ON}(P<.05)$. The inhibitory effect of PS-ON was also confirmed by reduced HCV core antigen and HCV RNA levels in the culture supernatant, as compared with those of the PO-ON-treated cells $(P<.05)$ (Figure $1 C$ and $D$ ). To evaluate further the efficacy of PS-ON against viral entry, HCVpp harboring genotype $1 \mathrm{~b}$ was used to infect Hep3B. The PS-ON blocked infection of HCVpp in a similar dose-dependent manner (Figure $1 E$ ). The PO-ON exhibited some inhibitory effect at high concentration, which could be attributed to noncytotoxic inhibition of cellular adherence by the polyanion nature of PO-ON. To assess whether the PS-ON inhibitory effect is specific for $\mathrm{HCV}$, retroviral pseudovirus carrying the vesicular stomatitis virus $\mathrm{G}$ protein (VSVGpp) was tested in the presence of PS-ON or PO-ON. Neither PS-ON nor POON had any effect on VSVGpp infection (Figure $1 F$ ). Furthermore, adenoviral infection was not inhibited by PS-ON (Supplementary Figure 1).

A series of homo- and heteropolymeric APs including poly G, A, T, C, TG AC, TC, and AG PS-ONs were tested for their inhibitory activities on HCV infection in both HCVcc and the HCVpp systems. These APs had similar inhibitory activities as the degenerate PS-ON with random sequence in the $\mathrm{HCVcc}$ system except for poly $\mathrm{G}$ and poly A (Figure $2 A$ ). Similar effects were also observed on HCV core antigen and HCV RNA levels in the culture supernatant (Figure $2 B$ and $C$ ). In the HCVpp system, these PS-ONs also had similar inhibitory effects (Figure 2D).

\section{AP Inhibition of HCV Infection Is Dependent on Size and Amphipathicity}

Different sizes of degenerate PS-ONs (6-, 10-, 20-, 30-, 40-, 50- and 80mer) were tested for their inhibitory activities in the HCVcc and HCVpp systems. Only PSONs with lengths of 40 mer or greater potently inhibited HCV infection (Figure $2 E$ ). This result was confirmed with the poly C PS-ONs (Supplementary Figure 2). To determine the requirement of amphipathicity for antiviral activity of these compounds, additional oligonucleo-tide analogs that had 
diminished hydrophilic character were prepared and include degenerate PS-ON analogs with either the base and/or the sugar removed (Supplementary Figure 3). An additional degenerate PS-ON analog containing the 2'-O-methyl ribose modification that does not affect the amphipathicity was tested. These analogs were tested for their inhibitory activities in the HCVcc and HCVpp systems. Only analogs that retained the amphipathic properties inhibited $\mathrm{HCV}$ infection (Figure $2 F$ ). These observations suggest that the amphipathic nature of these PS-ONs is necessary for inhibiting HCV infection.

\section{APs Inhibit Infection of Various Genotypes of HCV Without Affecting Replication and Cell Attachment}

To study the effects of APs on various HCV genotypes, HCVpp harboring E1/E2 glycoproteins from genotypes 1a, 1b, 2a, 3a, 4a, 5a, and 6a were tested. ${ }^{16}$ Infections by all genotypes were equally blocked by the degenerate PS-ON, whereas the degenerate PO-ON had no effect (Figure $3 A$ ). Similar observation was obtained with the poly C compounds (Supplementary Figure $2 D$ ).

The degenerate PS-ON compound was tested for its effect on viral replication in the HCV replicon system, which supports viral replication without the viral entry step. Genotype 1b and 2a subgenomic replicons were tested. Subgenomic replicon RNAs containing luciferase reporter were transfected into Huh7.5 cells, and the replication efficiency was determined in the presence of the PS-ON or PO-ON control. Neither PS-ON nor PO-ON displayed any antiviral activities in both subgenomic replicon systems (Figure $3 B$ ). To eliminate the possibility that PS-ON may induce an antiviral state with increasing time of exposure to cells, the HCV replicon assay was performed after exposure to either PS-ON or PO-ON for $24-48$ hours, and no difference in replication was observed (data not shown). Furthermore, Huh7.5 cells treated with PS-ON or PO-ON did not produce any detectable levels of type I interferons.

To dissect further the effect of PS-ON on viral entry, we applied the HCV-LP binding assay, which has been developed as a surrogate system to assess HCV binding to cells. ${ }^{24-26} \mathrm{HCV}$ LP were incubated in the presence of PS-ON and PO-ON for 1 hour at $4^{\circ} \mathrm{C}$ with Huh7.5 or Hep3B cells. Under this condition, virus attaches to the cells but does not enter. HCV patients' serum containing high-level of anti-E1/E2 antibodies was included as a control. The binding was detected with FITC-labeled mouse monoclonal anti-E2 antibodies (Figure 3C). The results showed that the anti-HCV antibodies inhibited the HCV-LP binding to the cells, whereas the PS-ON and PO-ON-treated HCV-LP did not inhibit HCV-LP binding. To validate the HCVLP binding assay, HCVcc binding to cells was performed in the presence of PS-ON, PO-ON, or HCV serum. HCV RNA bound to the cells was quantified to determine the percentage of binding. As shown in Figure $3 D, \mathrm{HCV}$ antibody significantly inhibited $\mathrm{HCV}$ cc binding to cells $(\sim 80 \%)$, whereas PS-ON and PO-ON had minor effects $(<20 \%)$. These results suggest that the target of inhibition by APs is at the postbinding, cell entry step.

To address the question of whether PS-ON binds to HCV directly to inhibit HCV infection, HCV binding assays were performed. First, in an immunoassay format using HCV-LP as a capture antigen, neither PS-ON nor PO-ON showed any significant binding to HCV-LP (Table 1). Second, sedimentation density gradient analysis did not show a preferential cosedimentation of $\mathrm{HCV} c c$ with PS-ON or PO-ON in comparison with the control preparation (Figure $3 E$ ), indicating that neither PS-ON nor PO-ON binds to $\mathrm{HCVcc}$ to any significant extent. The amount of PS-ON in the $\mathrm{HCV}$ cc or the control fraction was higher than that of PO-ON, probably reflecting the different physical properties of PS-ON and PO-ON. However, it is possible that low-affinity binding of HCV and PS-ON could be present and required for subsequent inhibitory action but not detected by the currently applied assays. 


\section{APs Inhibit Viral Internalization}

To determine which entry step that APs targets, the HCVpp assay was performed in the presence of concanamycin A $(25 \mathrm{nmol} / \mathrm{L})$, degenerate PS-ON $(100 \mathrm{nmol} / \mathrm{L})$, degenerate POON $(100 \mathrm{nmol} / \mathrm{L})$, or AP33+ALP98 monoclonal anti-E2 antibodies $(25 \mu \mathrm{g} / \mathrm{mL}$ total concentration) at $37^{\circ} \mathrm{C}$. Hep3B cells were first incubated with $\mathrm{HCVpp}$ at $4^{\circ} \mathrm{C}$ to allow binding and then at $37^{\circ} \mathrm{C}$ with various compounds after the inoculating HCVpp was removed.

Concanamycin A is known to inhibit HCV entry by preventing acidification of endosome. ${ }^{12}$ As shown in Figure 4A, AP33+ALP98 anti-E2 antibodies blocked HCV binding to the cells but had no effect on HCV entry. On the other hand, both concanamycin A and the degenerate PS-ON inhibited HCV entry.

To demonstrate that APs may inhibit $\mathrm{HCV}$ internalization at the fusion step, a viral fusion assay was performed with HCVpp or VSVpp as control. ${ }^{21}$ Degenerate sequence and poly C PS-ONs and the control PO-ONs were tested. Both PS-ON compounds showed significant inhibition of HCVpp fusion over their control PO-ON, whereas VSVGpp fusion was largely unaffected by either PS-ON or PO-ON (Figure $4 B$ and Supplementary Figure 4). The inhibitory effect of PS-ON on fusion was evident on both the rate and maximum of fusion in the assay.

\section{APs Inhibit HCV Infection In Vivo}

To test the efficiency of APs in vivo, sodium salts of amphipathic polymers (40mers) of poly $\mathrm{C}$ and poly $\mathrm{AC}$ and their respective PO-ON controls were prepared. Degenerate oligonucleotides were avoided because they might potentially contain $\mathrm{CpG}$ motifs, which could induce endogenous interferons, although in vitro testing did not reveal such a possibility. Human hepatocyte-transplanted uPA/SCID mice were treated with these compounds as described and inoculated with infectious HCV genotype $1 \mathrm{~b}$ patient serum. In this model, the production of human albumin in serum was monitored for the engraftment index of human hepatocytes. All mice showed robust and comparable human albumin concentrations that did not change significantly during the experimental period (Figure 5). Only 1 animal in the poly C PS-ON-treated group $(n=7)$ and 2 in the poly AC PS-ON-treated group $(n=5)$ were HCV positive. The remaining mice in both groups of mice were persistently negative. All 7 mice in the poly C PO-ON-treated mice (100\%) and 14 of 15 untreated mice (normal saline placebo) were $\mathrm{HCV}$ positive (93\%). The $P$ value was statistically significance between the PS-ON- and PO-ON-treated groups $(P<.05)$. To rule out the possibility that these protected mice were not intrinsically resistant to $\mathrm{HCV}$ infection despite robust human hepatocytes engraftment, some of them were rechallenged with infectious HCV inoculum several weeks later. They all became infected, supporting the specific inhibitory effect of APs on de novo HCV infection in this in vivo model.

\section{Discussion}

Current therapy for hepatitis $\mathrm{C}$ is based on peginterferon and ribavirin. However, the therapy is only effective in approximately half of the patients, and there is little option to those who fail current therapy. Recent advances in the development of small molecule inhibitors targeting the viral-encoded enzymes showed promise, ${ }^{27}$ but viral resistance to these drugs is a major clinical issue because HCV is highly variable with rapid viral proliferation and low-fidelity replication. Phosphorothiate modification of oligonucleotides was initially designed to reduce enzymatic degradation. This modification also increases the hydrophobicity of the phosphodiester backbone and thus imparts an amphipathic character to the oligonucleotide polymer. ${ }^{28}$ Recent studies showed that the amphipathic PS-ONs have a sequence-independent antiviral activity against HIV-1 and other viruses, ${ }^{14,29}$ suggesting that these compounds may exhibit a broad-spectrum antiviral activity. 
Our data showed that PS-ON blocked HCV infection in the HCVcc and HCVpp systems in a similarly dose-dependent manner, with 50\% inhibitory concentration in the nanomolar range. PS-ON had no effect on infection of VSVGpp (an enveloped RNA virus with mechanism of viral entry distinct from type I and II fusion) or adeno-virus (a nonenveloped DNA virus). The amphipathic nature of PS-ON is crucial for its anti-HCV property because PS-ON analogs lacking the amphipathicity are inactive. Polynucleotides are polyanions, a class of compounds that have been shown to interfere with a variety of viral infections. ${ }^{30,31}$ However, our data showed clearly that the polyanionic nature is not relevant to the PS-ON inhibitory activity because the control PO-ON is not active in HCV inhibition. Furthermore, the inhibitory effect of PS-ON could not be explained by the increased stability of the phosphorothioation because the control PO-ON has the 2'-O-methyl modification that also stabilizes the oligonucleotides. 14,23

The inhibitory activity of APs is sequence independent but length dependent. The degenerate APs were equally effective as the homo- and heteropolymeric sequences, with the exception of poly $\mathrm{A}$ and $\mathrm{G}$, which can form unique polypurine quartet structures in solution. ${ }^{32}$ The minimal length of PS-ON required for potent inhibitory activities is $40 \mathrm{mer}$, which appears to be the same for all active PS-ON compounds. This length-specific requirement may indicate a critical structural feature of the HCV entry process that is susceptible to these compounds. Although the degenerate PS-ON may contain CpG motif, the other hetero- and homopolymer PS-ONs tested herein are devoid of CpG motifs. The comparable anti-viral activity of these compounds to the degenerate PS-ON demonstrates that the antiviral activity is not mediated by the potential CpG-mediated induction of interferon. Furthermore, Huh7.5 cells express very little or none of the cell surface toll-like receptors involved in recognition of nucleic acid-based motifs, ${ }^{33}$ and we did not observe any production of endogenous type I inter-ferons in cells exposed to either PS-ON or PO-ON.

The inhibitory activity of PS-ON appears to target the postbinding and prereplication stage and possibly at the fusion step of HCV infection. The fusion process appears to be structurally conserved among many enveloped viruses and can be classified into types I and II. ${ }^{34}$ The type I membrane fusion is exemplified by the influenza and HIV-1 via hemagglutinin and gp41, respectively. The type II fusion includes the alpha-viruses and flaviviruses. ${ }^{34-36}$ It has been proposed that $\mathrm{HCV}$ uses a type II fusion process because of its similarity to flaviviruses. ${ }^{37}$ Our recent study suggests that $\mathrm{HCV}$ and flaviviruses are indeed structurally similar. ${ }^{38}$ It is conceivable that the fusion process of $\mathrm{HCV}$ may be susceptible to inhibition by the amphipathic structure of PS-ON, but further confirmation is necessary. HCV entry has been shown to occur via receptor-mediated endocytosis and is sensitive to lysosomotropic agents and inhibitors of vacuolar ATPases..$^{39}$ The finding that PS-ON acts at the postbinding step like concanamycin A and bafilomycin A1, which are potent inhibitors of the vacuolar ATPases, supports this hypothesis. Furthermore, all HCV genotypes appeared to be susceptible to the APs equally, suggesting that the process involved is highly conserved.

HCV entry involves multiple cellular factors, such as CD81, SR-B1, Claudin-1, heparin sulfate, DC-SIGN, and L-SIGN, and possibly LDL receptor. ${ }^{5-10,31}$ CD81 and Claudin-1 have been postulated to act on the postbinding step. ${ }^{6,40} \mathrm{SR}-\mathrm{B} 1$ is likely involved in an early viral entry step to the cells. Its interaction with apolipoproteins and cholesterol transfer property appear to be important for viral entry, ${ }^{41}$ possibly at the level of membrane fusion. ${ }^{42}$ The overall mechanism of HCV entry is complex and involves multiple factors and steps. The APs likely interact with 1 of these essential steps to abort HCV entry. The unique inhibitory effect of the APs on HCV infection makes it a valuable reagent to study the molecular pathway of $\mathrm{HCV}$ entry. The APs can also be developed as a molecular probe to image and dissect biochemically this complex process. 
Our study demonstrates that APs are potent inhibitors of HCV infection. APs are equally effective against all $\mathrm{HCV}$ genotypes and can inhibit de novo $\mathrm{HCV}$ infection in the human hepatocyte-transplanted uPA/SCID mouse model. This approach has the advantage of a novel and highly conserved target mechanism that is distinct from the small molecule inhibitors being developed clinically as well as the well-established pharmacology of antisense-based nucleic acid molecules in clinical trials. The effectiveness of this class of compounds in blocking de novo HCV infection supports its value in liver transplantation to prevent reinfection, which occurs invariably and presents a major problem for the management of these patients. ${ }^{43}$ So far, prophylactic reagents based on neutralizing antibodies have been disappointing in clinical trials of liver transplantation. ${ }^{44}$ Our studies illustrate the promise of this class of compounds as a potent antiviral against $\mathrm{HCV}$ and support its further development in the therapy of hepatitis $\mathrm{C}$.

\section{Supplementary Material}

Refer to Web version on PubMed Central for supplementary material.

\section{Acknowledgments}

The authors thank Charles Rice, Robert Purcell, Jens Bukh, and Thomas Baumert for providing various valuable reagents.

Funding

Supported in part by the Intramural Research Program of the National Institute of Diabetes and Digestive and Kidney Diseases, NIH, and a NIH Cooperative Research and Development Agreement (DK-06-0367) between NIDDK and REPLICor, Inc.

\section{Abbreviations used in this paper}

$\begin{array}{ll}\text { APs } & \text { amphipathic DNA polymers } \\ \text { HCV } & \text { hepatitis C virus } \\ \text { HCVcc } & \text { cell culture-generated HCV } \\ \text { HCVpp } & \text { HCV pseudoparticles } \\ \text { VSVGpp } & \text { vesicular stomatitis virus G protein pseudo-particle } \\ \text { PO-ON } & \text { phosphodiester oligonucleotide } \\ \text { PS-ONs } & \text { phosphorothioate oligonucleotides }\end{array}$

\section{References}

1. Liang TJ, Rehermann B, Seeff LB, et al. Pathogenesis, natural history, treatment, and prevention of hepatitis C. Ann Intern Med 2000;132:296-305. [PubMed: 10681285]

2. Feld JJ, Hoofnagle JH. Mechanism of action of interferon and ribavirin in treatment of hepatitis C. Nature 2005;436:967-972. [PubMed: 16107837]

3. Pawlotsky JM. Therapy of hepatitis C: from empiricism to eradication. Hepatology 2006;43:S207S220. [PubMed: 16447262]

4. Smith AE, Helenius A. How viruses enter animal cells. Science 2004;304:237-242. [PubMed: 15073366]

5. Bartosch B, Dubuisson J, Cosset FL. Infectious hepatitis C virus pseudo-particles containing functional E1-E2 envelope protein complexes. J Exp Med 2003;197:633-642. [PubMed: 12615904]

6. Evans MJ, von Hahn T, Tscherne DM, et al. Claudin-1 is a hepatitis C virus co-receptor required for a late step in entry. Nature 2007;446:801-805. [PubMed: 17325668] 
7. Hsu M, Zhang J, Flint M, et al. Hepatitis C virus glycoproteins mediate $\mathrm{pH}$-dependent cell entry of pseudotyped retroviral particles. Proc Natl Acad Sci U S A 2003;100:7271-7276. [PubMed: 12761383]

8. Lindenbach BD, Evans MJ, Syder AJ, et al. Complete replication of hepatitis C virus in cell culture. Science 2005;309:623-626. [PubMed: 15947137]

9. Lozach PY, Lortat-Jacob H, de Lacroix de Lavalette A, et al. DC-SIGN and L-SIGN are high affinity binding receptors for hepatitis C virus glycoprotein E2. J Biol Chem 2003;278:20358-20366. [PubMed: 12609975]

10. Scarselli E, Ansuini H, Cerino R, et al. The human scavenger receptor class B type I is a novel candidate receptor for the hepatitis C virus. EMBO J 2002;21:5017-5025. [PubMed: 12356718]

11. Bartosch B, Vitelli A, Granier C, et al. Cell entry of hepatitis C virus requires a set of co-receptors that include the CD81 tetraspanin and the SR-B1 scavenger receptor. J Biol Chem 2003;278:4162441630. [PubMed: 12913001]

12. Koutsoudakis G, Kaul A, Steinmann E, et al. Characterization of the early steps of hepatitis C virus infection by using luciferase reporter viruses. J Virol 2006;80:5308-5320. [PubMed: 16699011]

13. Rusconi S, Scozzafava A, Mastrolorenzo A, et al. An update in the development of HIV entry inhibitors. Curr Top Med Chem 2007;7:1273-1289. [PubMed: 17627557]

14. Vaillant A, Juteau JM, Lu H, et al. Phosphorothioate oligonucleotides inhibit human immunodeficiency virus type 1 fusion by blocking gp41 core formation. Antimicrob Agents Chemother 2006;50:1393-1401. [PubMed: 16569857]

15. Wakita T, Pietschmann T, Kato T, et al. Production of infectious hepatitis $C$ virus in tissue culture from a cloned viral genome. Nat Med 2005;11:791-796. [PubMed: 15951748]

16. Lavillette D, Tarr AW, Voisset C, et al. Characterization of host-range and cell entry properties of the major genotypes and subtypes of hepatitis C virus. Hepatology 2005;41:265-274. [PubMed: 15660396]

17. Owsianka A, Tarr AW, Juttla VS, et al. Monoclonal antibody AP33 defines a broadly neutralizing epitope on the hepatitis C virus E2 envelope glycoprotein. J Virol 2005;79:11095-11104. [PubMed: 16103160]

18. Kato T, Date T, Miyamoto M, et al. Detection of anti-hepatitis C virus effects of interferon and ribavirin by a sensitive replicon system. J Clin Microbiol 2005;43:5679-5684. [PubMed: 16272504]

19. Nanda SK, Herion D, Liang TJ. The SH3 binding motif of HCV (corrected) NS5A protein interacts with Bin1 and is important for apoptosis and infectivity. Gastroenterology 2006;130:794-809. [PubMed: 16530520]

20. Triyatni M, Saunier B, Maruvada P, et al. Interaction of hepatitis C virus-like particles and cells: a model system for studying viral binding and entry. J Virol 2002;76:9335-9344. [PubMed: 12186916]

21. Lavillette D, Bartosch B, Nourrisson D, et al. Hepatitis C virus glycoproteins mediate low pHdependent membrane fusion with liposomes. J Biol Chem 2006;281:3909-3917. [PubMed: 16356932]

22. Tateno C, Yoshizane Y, Saito N, et al. Near completely humanized liver in mice shows human-type metabolic responses to drugs. Am J Pathol 2004;165:901-912. [PubMed: 15331414]

23. Lamond AI, Sproat BS. Antisense oligonucleotides made of 2 '-O-alkylRNA: their properties and applications in RNA biochemistry. FEBS Lett 1993;325:123-127. [PubMed: 7685712]

24. Steinmann D, Barth H, Gissler B, et al. Inhibition of hepatitis C virus-like particle binding to target cells by antiviral antibodies in acute and chronic hepatitis C. J Virol 2004;78:9030-9040. [PubMed: 15308699]

25. Baumert TF, Vergalla J, Satoi J, et al. Hepatitis C virus-like particles synthesized in insect cells as a potential vaccine candidate. Gastroenterology 1999;117:1397-1407. [PubMed: 10579981]

26. Wellnitz S, Klumpp B, Barth H, et al. Binding of hepatitis C virus-like particles derived from infectious clone H77C to defined human cell lines. J Virol 2002;76:1181-1193. [PubMed: 11773394]

27. Pawlotsky JM, Chevaliez S, McHutchison JG. The hepatitis C virus life cycle as a target for new antiviral therapies. Gastroenterology 2007;132:1979-1998. [PubMed: 17484890]

28. Agrawal S, Tang JY, Brown DM. Analytical study of phosphorothioate analogues of oligodeoxynucleotides using high-performance liquid chromatography. J Chromatogr 1990;509:396-399. [PubMed: 2211903] 
29. Lee AM, Rojek JM, Gundersen A, et al. Inhibition of cellular entry of lymphocytic choriomeningitis virus by amphipathic DNA polymers. Virology 2008;372:107-117. [PubMed: 18022208]

30. Moulard M, Lortat-Jacob H, Mondor I, et al. Selective interactions of polyanions with basic surfaces on human immunodeficiency virus type 1 gp120. J Virol 2000;74:1948-1960. [PubMed: 10644368]

31. Barth H, Schafer C, Adah MI, et al. Cellular binding of hepatitis C virus envelope glycoprotein E2 requires cell surface heparan sulfate. J Biol Chem 2003;278:41003-41012. [PubMed: 12867431]

32. Kim J, Cheong C, Moore PB. Tetramerization of an RNA oligonucleotide containing a GGGG sequence. Nature 1991;351:331-332. [PubMed: 1709723]

33. Preiss S, Thompson A, Chen X, et al. Characterization of the innate immune signalling pathways in hepatocyte cell lines. J Viral Hepat 2008;15:888-900. [PubMed: 18673429]

34. Kielian M, Rey FA. Virus membrane-fusion proteins: more than one way to make a hairpin. Nat Rev Microbiol 2006;4:67-76. [PubMed: 16357862]

35. Kielian M. Class II virus membrane fusion proteins. Virology 2006;344:38-47. [PubMed: 16364734]

36. Lescar J, Roussel A, Wien MW, et al. The fusion glycoprotein shell of Semliki Forest virus: an icosahedral assembly primed for fusogenic activation at endosomal $\mathrm{pH}$. Cell 2001;105:137-148. [PubMed: 11301009]

37. Yagnik AT, Lahm A, Meola A, et al. A model for the hepatitis C virus envelope glycoprotein E2. Proteins 2000;40:355-366. [PubMed: 10861927]

38. Yu X, Qiao M, Atanasov I, et al. Cryo-electron microscopy and three-dimensional reconstructions of hepatitis C virus particles. Virology 2007;367:126-134. [PubMed: 17618667]

39. Tscherne DM, Jones CT, Evans MJ, et al. Time- and temperature-dependent activation of hepatitis C virus for low-pH-triggered entry. J Virol 2006;80:1734-1741. [PubMed: 16439530]

40. Cormier EG, Tsamis F, Kajumo F, et al. CD81 is an entry core-ceptor for hepatitis C virus. Proc Natl Acad SciU S A 2004;101:7270-7274.

41. Bartosch B, Verney G, Dreux M, et al. An interplay between hypervariable region 1 of the hepatitis $\mathrm{C}$ virus E2 glycoprotein, the scavenger receptor BI, and high-density lipoprotein promotes both enhancement of infection and protection against neutralizing antibodies. J Virol 2005;79:8217-8229. [PubMed: 15956567]

42. Dreux M, Boson B, Ricard-Blum S, et al. The exchangeable apolipoprotein ApoC-I promotes membrane fusion of hepatitis C virus. J Biol Chem 2007;282:32357-32369. [PubMed: 17761674]

43. Samuel D, Bizollon T, Feray C, et al. Interferon- $\alpha 2 b$ plus ribavirin in patients with chronic hepatitis C after liver transplantation: a randomized study. Gastroenterology 2003;124:642-650. [PubMed: 12612903]

44. Schiano TD, Charlton M, Younossi Z, et al. Monoclonal antibody HCV-AbXTL68 in patients undergoing liver transplantation for HCV: results of a phase 2 randomized study. Liver Transpl 2006;12:1381-1389. [PubMed: 16933235] 

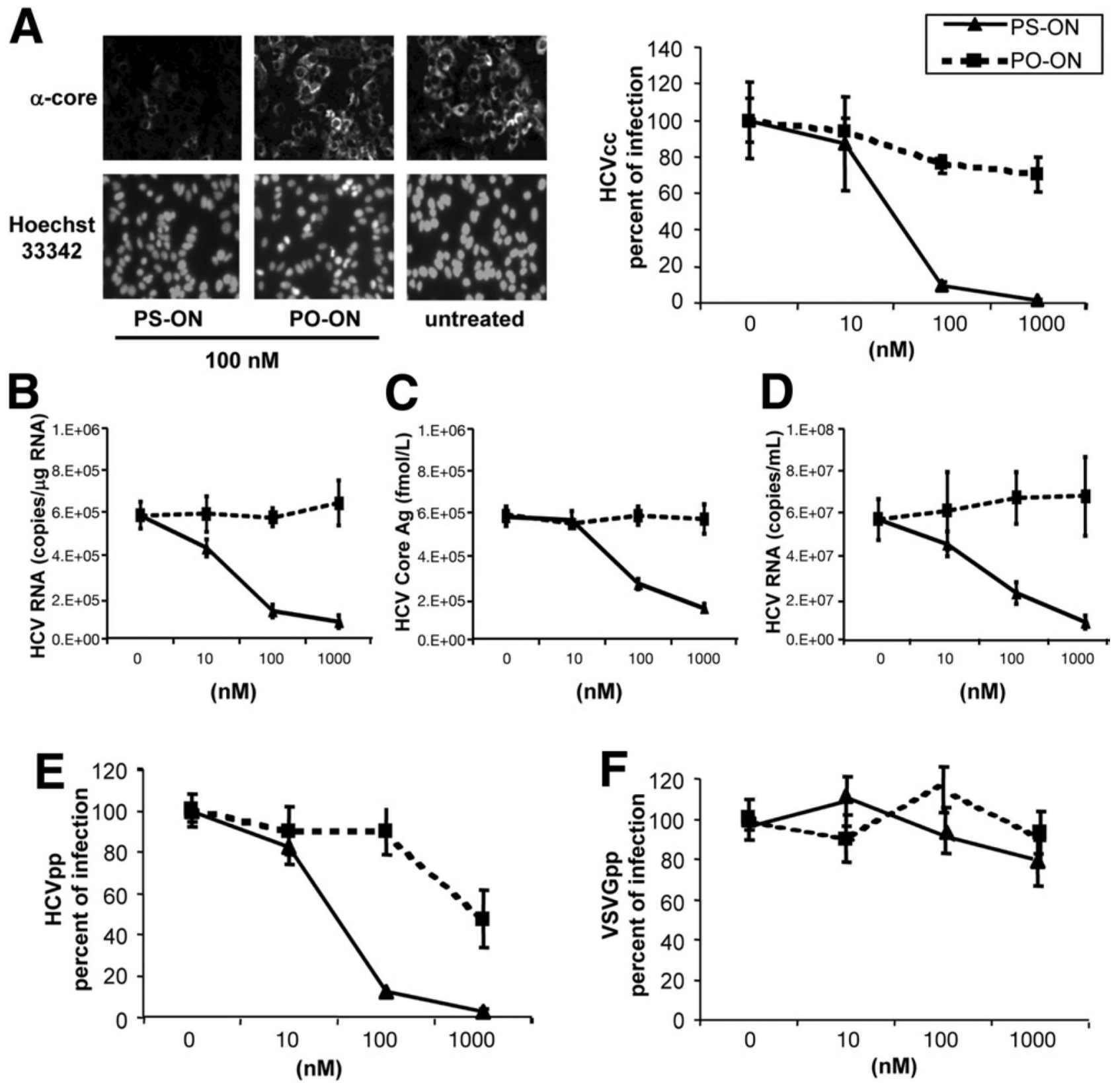

Figure 1.

Effect of PS-ON on HCV infection. (A) Huh7.5 cells were infected with HCVcc in the presence of various concentrations of 40mer PS-ON or PO-ON (degenerate sequence). Two days after infection, infected cells were detected by immunofluorescence assay using anticore antibodies (left panel). Percentage of infection was determined by dividing the number of HCVexpressing cells in treated over the untreated cells (right panel). The intracellular HCV RNA levels $(B)$ and HCV core Ag $(C)$ and supernatant HCV RNA $(D)$ levels in the culture medium were determined. Hep3B cells were infected with $(E)$ HCVpp genotype 1 b or $(F)$ VSVGpp and treated with various concentrations of PS-ON and PO-ON, and lucif-erase activities were determined 2 days later. Results are shown as percentages of infection + standard deviations (SD). 

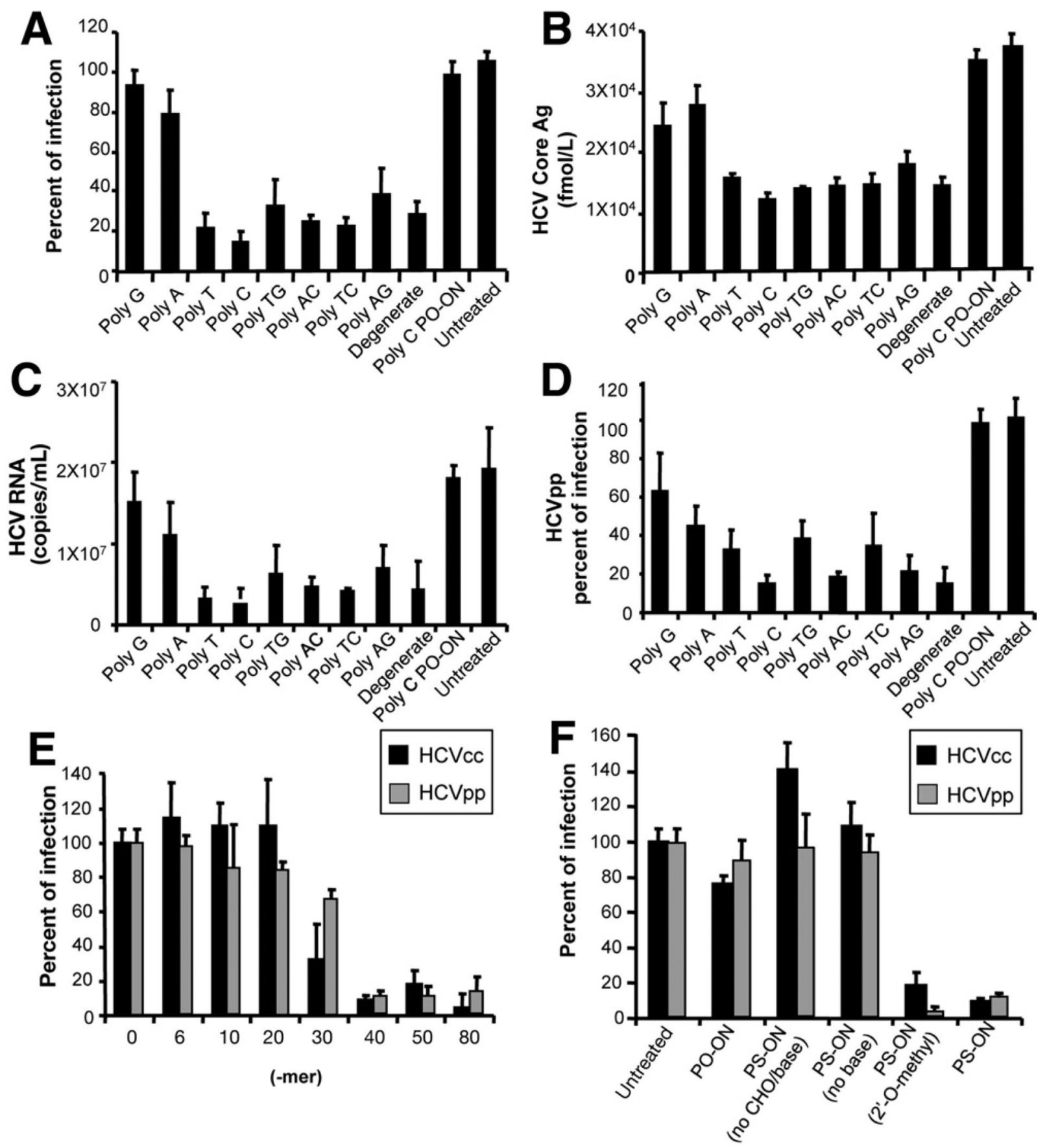

Figure 2.

Sequence-independent and size- and phosphorothioation-dependent effects of PS-ON on HCV infection. A series of 40mer PS-ONs with specific sequences including poly poly $\mathrm{G}, \mathrm{A}, \mathrm{T}, \mathrm{C}$, TG AC, TC, and AG were tested for their inhibitory effect on HCV infection. (A) HCVcc was inoculated with Huh7.5 cells and treated with $100 \mathrm{nmol} / \mathrm{L}$ of these homo- and heteropolymeric PS-ONs. Expression of HCV core was detected by immunofluorescence assay using anticore antibodies. $(B)$ The HCV core Ag titers and $(C)$ HCV RNA levels in the culture medium were determined. $(D)$ Hep3B cells were infected with HCVpp geno-type $1 \mathrm{~b}$ and treated with these various PS-ONs at $100 \mathrm{nmol} / \mathrm{L}$, and luciferase activities were determined 2 days later. $(E)$ Various sizes of PS-ON (10 - 80mers) at $100 \mathrm{nmol} / \mathrm{L}$ were tested in the HCVcc and HCVpp 
systems. $(F)$ Various structures of oligonucleo-tides, PS-ON analogue with phosphorothioate backbone but without the sugar or base, and PS-ON analogue with 2=-O-methyl ribose modification, were synthesized. Each 40 mer oligo-nucleotide at $100 \mathrm{nmol} / \mathrm{L}$ was tested in the HCVcc and HCVpp systems. All results are shown as percentages of infection + SD. 

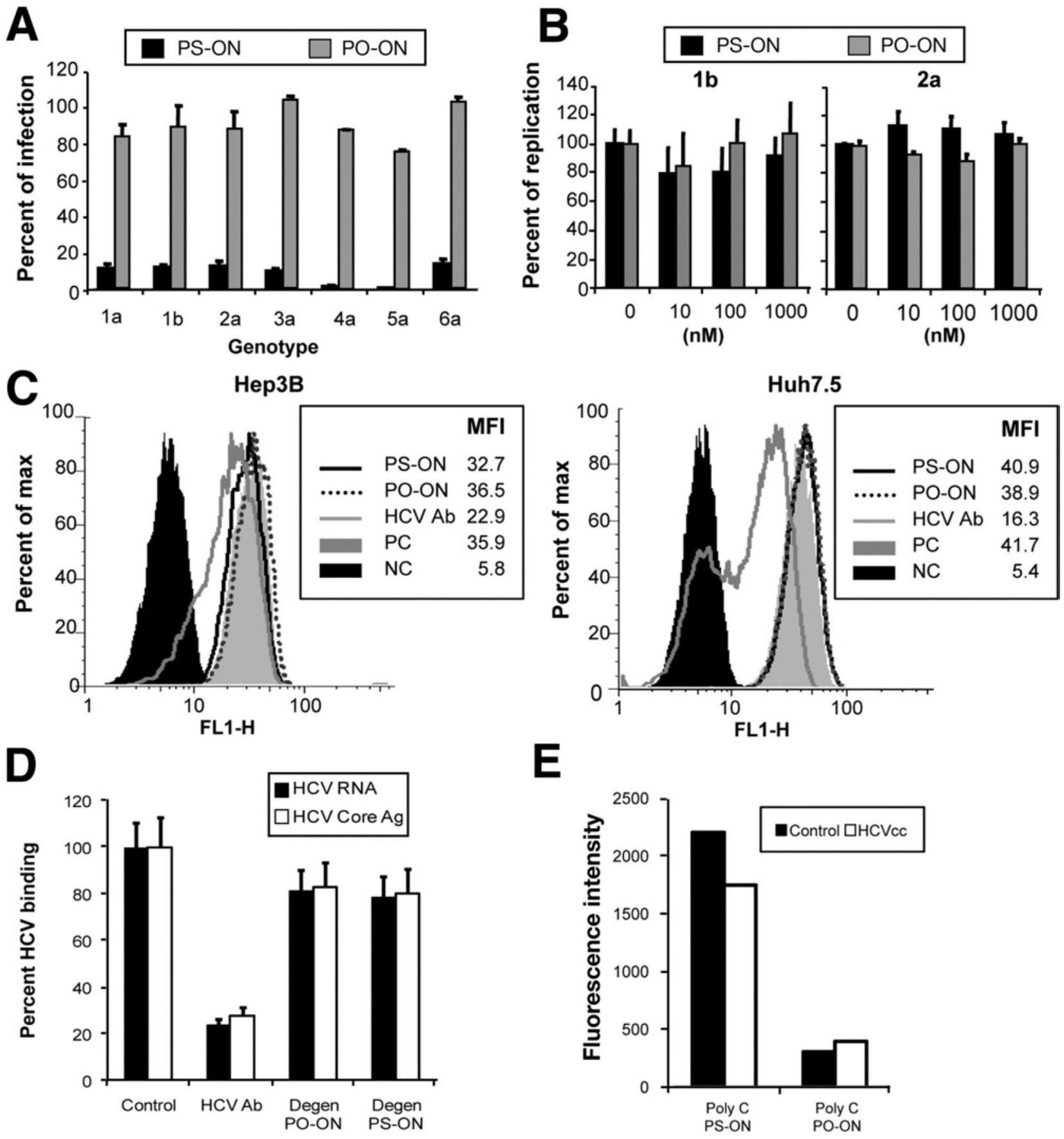

Figure 3.

Effects of PS-ON on infection of various HCV genotypes, HCV replication, and cell binding. (A) HCVpp harboring E1/E2 glycoproteins from genotypes 1a, 1b, 2a, 3a, 4a, 5a, and 6a were inoculated into Hep3B cells and simultaneously treated with $100 \mathrm{nmol} / \mathrm{L}$ of degenerate PS-ON and PO-ON (40mer). Luciferase activities were determined 2 days later. (B) Subgenomic RNA of genotype $1 \mathrm{~b}$ Con 1 or 2a JFH1 were transfected into Huh7.5 cells. Four hours after transfection, a set of transfected cells was harvested as a control for transfection efficacy, and the remaining cells were treated with $100 \mathrm{nmol} / \mathrm{L}$ of PS-ON and PO-ON. Cells were then harvested at 72 hours posttransfection and luciferase activities determined. The replication level was presented as the ratio of the luciferase activity of the sample at 72 hours over that of 
4 hours. Percentages of replication were determined by dividing the replication level of treated over that of untreated samples. (C) Hep3B and Huh7.5 cells were incubated with $20 \mu \mathrm{g} / \mathrm{mL}$ HCV-LP and $100 \mathrm{nmol} / \mathrm{L}$ PS-ON or PO-ON at $4{ }^{\circ} \mathrm{C}$ for 1 hour. The cells were washed and incubated with anti-E2 ALP98 monoclonal antibody for 30 minutes followed by FITC-labeled goat anti-mouse immunoglobulin for 30 minutes at $4^{\circ} \mathrm{C}$. HCV-LP binding was analyzed by flow cytometry. The black filled peaks are negative controls without the anti-E2 antibody. The gray filled peaks are positive controls showing HCV-LP binding without any compounds. The black solid lines and gray dotted lines represent treatments with PS-ON and PO-ON,

respectively. The gray solid line represents samples in the presence of HCV serum that has been shown previously to inhibit HCV-LP binding. The mean fluorescence intensity (MFI) of each sample is shown. (D) HCVcc was incubated with Huh7.5 cells in the presence of HCV

serum PS-ON or PO-ON at $4^{\circ} \mathrm{C}$ for 1 hour. The unbound virus was washed off, and the bound $\mathrm{HCV} c \mathrm{c}$ was determined by HCV RNA quantification and $\mathrm{HCV}$ core Ag assay. (E) HCV cc was incubated with Cy3-labeled degenerate PS-ON or PO-ON (40mer) and subjected to iodixinol density gradient analysis as described in the online Supporting Document. Control preparation generated the same way was used for comparison. The fluorescence intensity of the fraction where infectious HCV sedimented was determined and shown. 

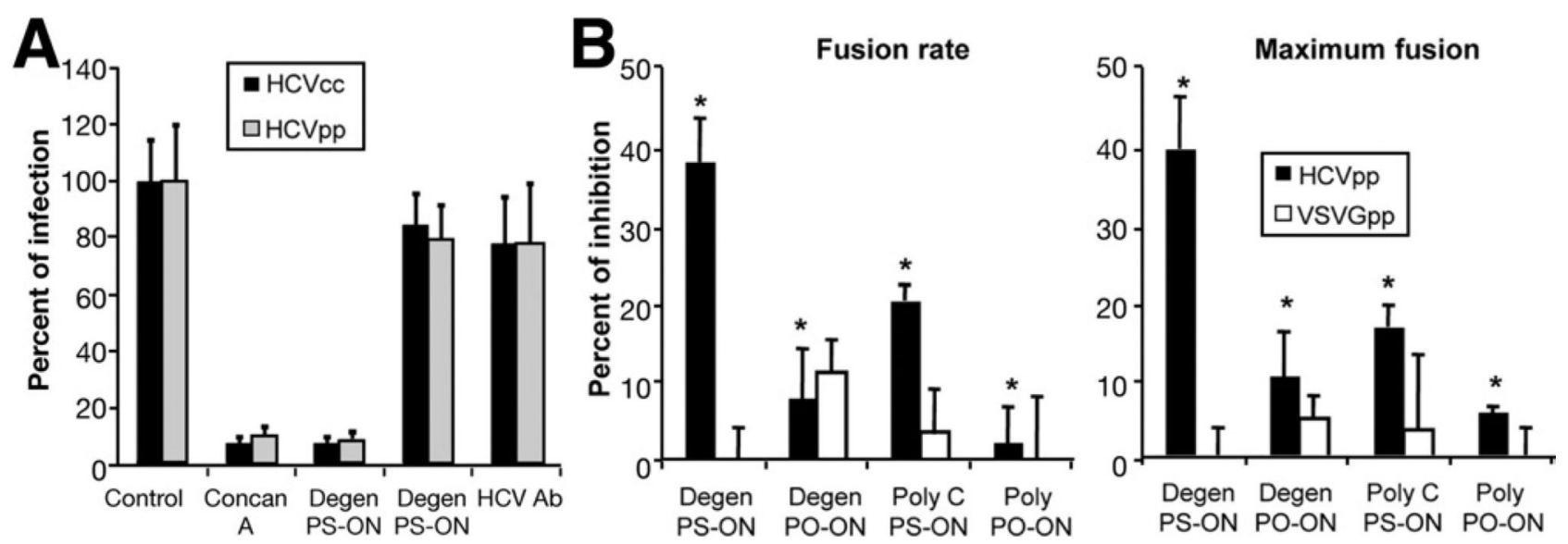

Figure 4.

Effects of PS-ON on HCV viral entry. (A) Hep3B cells were incubated with $\mathrm{HCVpp}$ at $4{ }^{\circ} \mathrm{C}$ for 1 hour to bind the virus and washed to remove the unbound virus. Cells were then incubated with fresh culture medium containing $25 \mathrm{nmol} / \mathrm{L}$ concanamycin A, $100 \mathrm{nmol} / \mathrm{L}$ PS-ON, 100 $\mathrm{nmol} / \mathrm{L}$ PO-ON, or $25 \mu \mathrm{g} / \mathrm{mL}$ (total concentration) AP33+ALP98 monoclonal antibodies at $37^{\circ} \mathrm{C}$ for 16 hours. The luciferase activities were determined 24 hours later. Results are shown as percentages of infection + SD. (B) Fusion assay was performed with HCVpp or VSVGpp in the presence of PS-ON (degenerate or poly $\mathrm{C}$ ) or the PO-ON controls. The results are expressed as mean percentages (means $+\mathrm{SD}$ ) of inhibition of either the fusion rate at the origin of the fusion kinetics (left panel) or the maximum fusion of the curve at $500 \mathrm{~S}$ (right panel) relative to incubation in the absence of the compounds. The fusion curves are shown in Supplementary Figure $4 . * P<.05$ comparing the PS-ON and the corresponding PO-ON in the HCVpp fusion assay. 

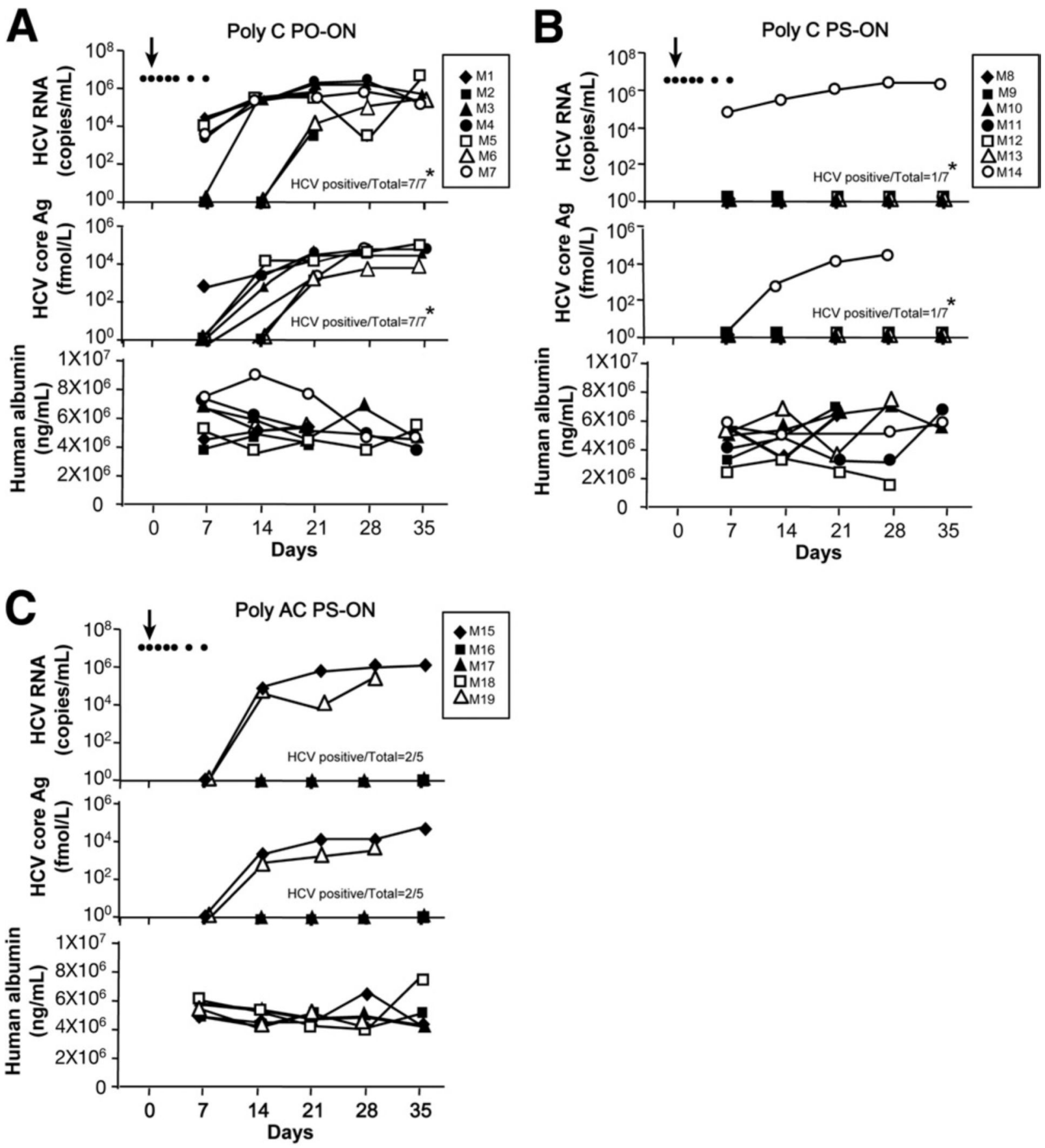

Figure 5.

Effects of PS-ON on HCV infection in vivo. Human hepatocytes-transplanted uPA/SCID mice were treated intraperitoneally with $10 \mathrm{mg} / \mathrm{kg}$ of PS-ON (poly C) $(\mathrm{n}=7)$ or (poly AC) $(\mathrm{n}=5)$ on days $-1,0,1,3,5$, and 7 (indicated by dots). The corresponding control PO-ON (poly C) was also tested $(n=7)$. A fourth group of mice did not receive any compounds $(n=15)$. The mice were intravenously inoculated on day 0 with $\mathrm{HCV}$ patient serum containing $3.9 \times 10^{3}$ copies of HCV genotype $1 \mathrm{~b}$ (indicated by arrow). Serum samples were obtained on days 0 (prior to HCV inoculation), 7, 14, 21, 28, and 35 for HCV RNA and human albumin determination. HCV core antigen was also measured and showed the same results as the HCV RNA determination. 


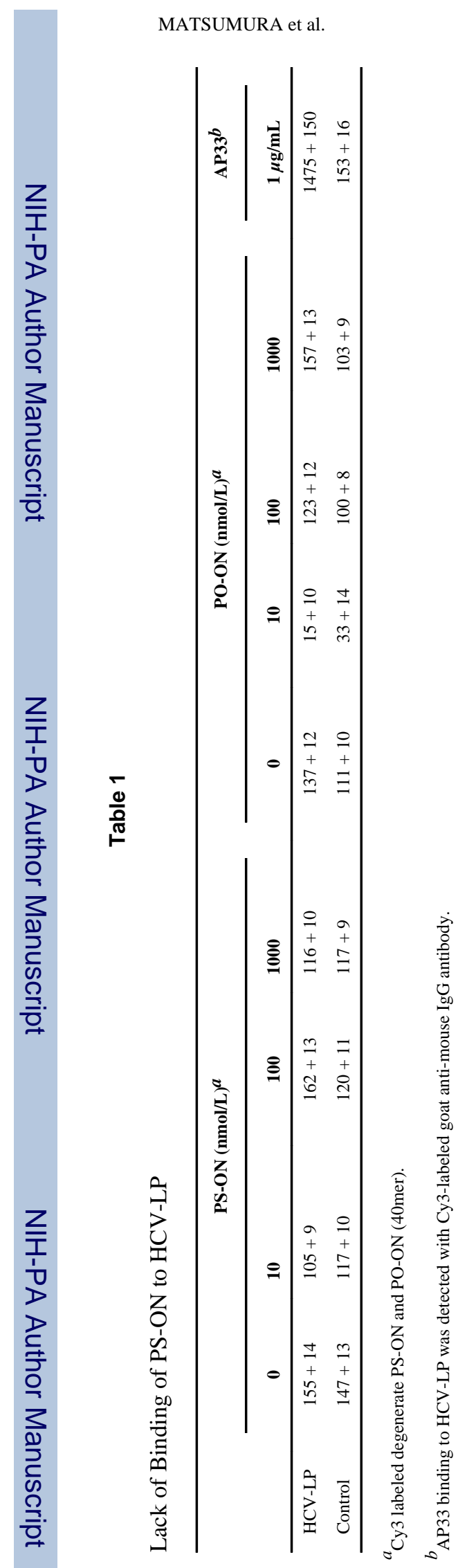

Page 17 